\title{
Fundación murciana de la Orden de San Jerónimo
}

\author{
JUAN TORRES FONTES *
}

Causas muy diversas motivarían el considerable retraso que supuso el establecimiento de los jerónimos en tierras murcianas. La primera de ellas responde al orden geográfico, como sería su invariable ubicación en el contexto peninsular de los siglos medievales; apéndice marginal de la Corona de Castilla, en su asfixiante situación motivada por la triple frontera envolvente de Granada, Aragón y Mediterráneo, más al cierre casi completo que suponía el compacto señorío-marquesado de Villena. Y las consecuencias: una población muy escasa en todo el adelantamiento, ocasionada, durante tres siglos por la permanente inseguridad que se extendía por todo el territorio. Inseguridad, despoblación, pobreza, dificultades de todas clases frenaron innovaciones y el estar «al día» respecto a los cambios que se fueron introduciendo en los reinos castellanos. Es relativamente frecuente encontrar acuerdos concejiles de enviar mensajeros a Toledo para "saber nuevas del reino", o a Valencia en solicitud de información sobre cuestiones muy diversas. Aislamiento y lejanía de la Corte, despreocupación de ésta y escasez de medios serían causa en parte del retraso en la evolución de costumbres y en la recepción de novedades.

En el orden religioso, por el contrario, se iba a producir un profundo cambio con el nombramiento de Pablo de Santa María como obispo de Cartagena tras el turbulento episcopado de don Fernando de Pedrosa, un tanto politizado por la ayuda prestada a sus parientes en la pugna «Manueles y Fajardos». Si por la documentación con que contamos se

\footnotetext{
* Universidad de Murcia.
} 
desprende que sólo visitó y por contados días una sola vez su diócesis, su absentismo no fue olvido, pues mantuvo continua comunicación con sus vicarios y aprovechó su disposición preponderante en la Corte real para imponer sus criterios frente a las disposiciones concejiles sobre los mudéjares de Alcantarilla, vasallos suyos, a veces descompensadas y lejos de la realidad de los hechos. De igual forma la prolongada permanencia de San Vicente Ferrer en territorio murciano en aquellas fechas, impulsaría también a una reforma de costumbres y que durante mucho tiempo se mantuvieran disposiciones tendentes a una indudable mejora de la vida social e incremento del sentimiento religioso de los murcianos.

Derivada de los años del episcopado de Pablo de Santa María, olvidadas sus desmesuradas censuras eclesiásticas, otra vía por él iniciada y mantenida proporcionaría resultado provechosos y prolongados. Sería ésta la relación que desde entonces se establece entre Murcia y Burgos durante todo el siglo $\mathrm{XV}$, fundamentalmente en el orden eclesiástico, al que seguirian derivaciones de distinto alcance, entre otras las culturales. Todo ello supondría la llegada desde Burgos de distintas personas; unos, clérigos, que pronto ocuparon las más importantes dignidades del cabildo catedralicio, y otras, personal civil de distintos oficios, desde un barbero hasta un destacado pintor, cuya "colocación" parece derivarse de la influencia de la permanencia de estos rectores de la vida religiosa. Hubo un menor intercambio de quienes marcharon a Burgos para ampliar estudios, como fue Diego Rodríguez de Almela, hijo de Alonso Martínez de Almela, escribano del cabildo catedralicio, cuyo aprendizaje al lado de Alonso de Cartagena, hijo y sucesor de don Pablo de Santa María en el obispado de Burgos, y después con don Juan Manrique, arcipreste de Valpuesta, le proporcionarían unos conocimientos variados y profundos, una base cultural, que pudo hacer pública a su vuelta a Murcia en sus reuniones con la gente más ilustrada de la ciudad y con la publicación de diversos tratados, cartas y estudios que fueron las primeras obras impresas en Murcia después del Misal Cartaginense, editado en 1485.

\section{EL FALLIDO PROPÓSITO DE FERNANDO ALFONSO DE OÑA}

Un clérigo burgalés que llega a Murcia siguiendo la vía abierta por Pablo de Santa María, y es posible que lo hiciera en su episcopado, y que 
fue tesorero y deán del cabildo de Cartagena y vicario general de la diócesis durante más de veinticinco años, fue Fernando Alfonso de Oña.

En su testamento, que se fecha en 1445, aunque todavía seguía en su cargo seis años más tarde -amplio y enumerativo-, proporciona abundantes noticias familiares: los nombres de sus padres, segunda mujer paterna, abuelos paternos y maternos, hermanos, tíos, primos, cuñado, servidores, entre ellos uno su capellán muerto en Roma, escuderos, criados, etc..., así como la diversidad de bienes que poseía en Oña y en Murcia, y las mandas y legados propios de estas disposiciones de última voluntad. De todas ellas nos interesan dos aspectos: uno, indicar simplemente cuál era el "clan» familiar; la relación influyente que pudieron ejercer sus parientes para el acceso de Fernando Alfonso de Osma y al mismo tiempo cuál era la corriente procedente de Burgos que desde el episcopado de Pablo de Santa María es perceptible en el cabildo catedralicio murciano. Otro, su intento de establecer la Orden jerónima en Murcia.

A su llegada a Murcia debió acogerle la sombra protectora de García Fernández, «fundador del espital de Santa Maria de Gracia, que establecio mi señor tio, maestresala que fue», y junto a cuya tumba dispuso también la suya; pero no era un solo tío, sino que había otro llamado Alfonso Fernández de Oña, canónigo, y canónigo igualmente había sido su hermano Juan Antonio, ya difunto cuando redactaba su testamento, y lo era su primo Andrés Fernández de Oña. Cinco clérigos procedentes de Oña, quizá los habría de otros lugares de la diócesis burgalesa y sin incluir a un Pedro de Oña, "mitrado". Una relación familiar en cadena, que permite valorar cómo se lograba la continuidad en la ocupación de puestos destacados en el Cabildo y modo también de colocar el excedente familiar.

En su juventud el deán Oña debió mantener estrechos contactos con el monasterio jerónimo de Fresdeval y sentir cierta atracción y afecto por la vida monástica de los frailes jerónimos, pues en su testamento no los olvida: «Iten, mando que por devoçion al monesterio de frayles de Desfresdeval, de la horden de Sant Jeronimo, que es çerca de Burgos, el qual fizo el adelantado Martin, para una casulla o capa mill e quinientos maravedis de dos blancas, porque los freyles rueguen a Dios por mi anima». No fue esto sólo, pues habiendo obtenido la propiedad y señorío de unas tierras regadas por la acequia de Benavía por donación testamentaria de doña Sancha González Aguilar, pensó en construir en ellas un monasterio jerónimo. La disposición de doña Sancha era: el señorío y 
propiedad para el deán, y cuanto abonaban los mudéjares censatarios de dicha alquería para el Cabildo con obligación de celebrar misas por su alma, la de su padre y de un sobrino. Firme en su propósito, Fernando Alfonso de Oña comenzó a redimir los censos, que él por su parte continuó abonando al Cabildo, como medio para disponer libremente de las setenta tahúllas que aproximadamente tenía dicha alquería. Obtuvo primero la licencia episcopal indispensable: "por serviçio de Dios e de Sant Geronimo, yo ove liçençia e facultad de mi señor el obispo de Cartajena de fazer un monesterio de la dicha horden de Sant Jernomo en la mi torre e alqueria que es en Beninabia, açerca de la Puebla de Santaren". $\mathrm{Su}$ testamento no es muy explícito a cualquier referencia respecto a cuanto proyectaba, lo que sin duda se contendría en disposiciones anteriores, que no tenían cabida en éste, ya que abandonaba su idea de fundar dicho monasterio en sus tierras.

No deja de ser curiosa una de las causas de su fracaso. Aunque luchó tenazmente para redimir la totalidad de las tierras acensadas a los cultivadores mudéjares, no logró convencer a Mosquito y a su yerno Pardal, que mantenían acensadas unas dieciocho tahúllas, lo que suponía no sólo una merma importante, sino que hacía aún más problemática la cuestión por el lugar en que estaban situadas dichas tahúllas. Lo que muestra que no era fácil quebrantar los derechos de los mudéjares, aunque fueran censatarios de la Iglesia y que quien lo intentaba era el señor de dicho lugar, que a la vez era también deán y vicario general del obispado. $Y$ no debió ser por diferencias económicas en cuanto a su coste.

Tal dificultad enfrió ánimos y ya entonces todo fueron dificultades: «yo esto cargado de debdas e cargos de diversas personas»; también entonces le preocupó su edad, aunque viviría por lo menos seis años más: «la brevedad de mi vida el dicho monesterio non se puede fazer nin yo tengo tantos bienes que yo pudiese dejar para lo hedificar", fueron las explicaciones por las que decidió desistir de su fundación. Tomada esta decisión, ordenaba que cuanto quedara después de cumplir sus legados y mandas, pago de deudas y ciertos compromisos, pasara al Cabildo, y si fuera posible construyeran en aquellas tierras una iglesia para los cristianos que vivían en sus cercanías, pues «por mengua de iglesia... andan los rectores diziendo las misas por las torres e por los lugares que no son tan honestos».

Pese a sus temores y la enfermedad que tuvo, sin duda grave, que le llevó a redactar su testamento y abandonar la idea de crear un mo- 
nasterio jerónimo, no fue mortal, pues con el mismo ánimo que siempre mostró en el largo gobierno de la diócesis, en 1451 conseguía como deán y para el cabildo que el municipio les autorizara a construir un noria en la acequia del Turdebal -licencia un tanto discutida y dificultosacon lo cual pudieron poner en riego sus tierras algaidonares, esto es, regadas por pértiga 0 algaidón; la construcción de la gigantesca noria permitiría muy poco después el riego de los secanos de su señorío de Alcantarilla.

Se precisa en su testamento la ilusión primera que tuvo en ir redimiendo censos, en la construcción de una torre, palomares, horno y otros edificios: pajeras, cuadras e incluso un huerto cercado, con árboles frutales e incluso "planté un majuelo", y su sincero convencimiento de no poder salvar los impedimentos que se oponian a su anhelo, que le obligaban a abandonar su empresa. Y su decisión final, de que si todo cuanto disponía se cubría con los bienes que dejaba y quedaba libre la alquería, la donaba al Cabildo aconsejando la entregaran de nuevo a censo a mudéjares de Alcantarilla o La Puebla y que a cambio de ello rezasen doce misas anuales por su eterno descanso.

\section{LA FUNDACIÓN DE ALONSO VOZMEDIANO DE ARRÓNIZ}

La historia del monasterio jerónimo de San Pedro de La Nora estaba profundamente documentada por la extraordinaria riqueza archivística que allí se guardaba antes de 1936 y que permitió al P. Blanco Trías, SJ, con amplio apoyo documental, ofrecer una síntesis de su fundación, personalidad de su fundador y una larga relación de los legajos y su contenido. Archivo dispersado o destruido - sólo conozco un códice- lo que imposibilita hoy día aprovechar esta amplísima documentación para nuevos estudios.

Alonso Vozmediano de Arróniz, que antepuso el apellido materno al paterno porque su hermano Sancho González de Arróniz utilizó el más familiar de sus principales ascendientes, en tanto que otro hermano, $\mathrm{Pe}$ dro, quedaba con el solo apellido Arróniz, fue quien dispuso que a falta de sucesión de su hijo y sobrinos la fundación de un monasterio jerónimo en su señorio de La Nora, en cuya iglesia de San Pedro dejó ordenado su enterramiento y en donde fue sepultado el año 1557. 
Los Arróniz y sobre todo los que llevaron el nombre y apellidos Sancho González de Arróniz ocuparon desde mediados del siglo XIV puestos rectores en el concejo murciano. Sería un Sancho González de Arróniz quien en los años finales del siglo xIV crearía un señorío menor con exclusivo trabajo mudéjar en el lugar de Santaren, junto a la acequia de su nombre y el río Segura. No fue el único intento por entonces, pues el rendimiento económico de estos pequeños señoríos, como sus vecinos los de abadengo de Alcantarilla y Alguazas, así como la afluencia de mudéjares procedentes de las encomiendas santiaguistas y su acomodo en la huerta, propiciarian la creación de nuevos señoríos sin jurisdicción y no de gran extensión superficial. Lo intentó al otro lado del Segura en diciembre de 1399 el adelantado Lope Pérez de Davalos, quien habiendo comprado la heredad del Javalí, tierras de secano, pidió autorización al concejo para la construcción de una noria que elevara el agua a la altura de sus tierras. No fue posible entonces. Ocho años más tarde era su viuda Mencía de Cervatos quien volvía a solicitar la oportuna licencia concejil. Tampoco tenemos constancia que así lo hiciera.

Probablemente fue otro Sancho González de Arróniz, regidor perpetuo de Murcia, quien llevó a cabo su construcción y con ella la creación de un señorío en La Ñora hacia 1421, llamado anteriormente las "Almagarras o Algamarra de los Moros" en Beniscornia, por lo que tuvo enconadas disputas con el concejo, denunciado como usurpador de la jurisdicción de la ciudad y aun en disputa la propiedad de dicho lugar. El licenciado Alfonso Núñez de Toledo, designado para enjuiciar tales casos, sentenció en 1436 la restitución a la ciudad de Murcia de varios términos que le habían sido usurpados. No tendría efecto y en 1440 el oidor real Alonso Fernández de Cascales llevaba a cabo la constitución de su señorío mudéjar de La Puebla de Cascales, más tarde Puebla de Soto y a él siguió Sancho González de Arróniz merced a una carta real de Juan II, de 30 de mayo de 1442, por la que le autorizaba a fundar en su heredad de La Nora una puebla de hasta sesenta vecinos moros y en una extensión de unas cien tahúllas. Relatar las actividades políticas de González de Arróniz, cuñado de Fajardo y al frente de la facción que seguía fielmente los dictados de don Juan Pacheco, en nombre del príncipe don Enrique, ocuparía mucho espacio y quedaría fuera de lugar por la extensión del tema.

Heredado el señorío por su hijo Manuel de Arróniz, cuyas participaciones tienen lugar en 1477, casó con María de Vozmediano, hija de Alonso de Vozmediano, comendador de Moratalla, muerto violentamente por sus vasallos hacia 1465, y quien en su testamento de 1510 dejaba 
cuanto poseía a sus hijos Sancho González de Arróniz, Pedro de Arróniz y Alonso Vozmediano de Arróniz; éste mejorado por su madre al dejarle como su heredero universal en su testamento de 18 de septiembre de 1507.

Alonso Vozmediano recibió como herencia paterna el lugar, torre, casa y alquería de La Ñora baja, si bien años más tarde pudo conjuntar la mayor parte de la herencia paterna, La Ñora alta, porque habiendo sido condenado a muerte su hermano Sancho González de Arróniz -quizá por su participación en las Comunidades- y a la pérdida de la mitad de sus bienes, vendidos éstos en pública subasta el año 1524, pudo adquirirlos Vozmediano por cuatrocientos mil maravedís.

Los datos concretos de la biografía de Alonso Vozmediano de Arróniz quedan indicados al señalar que fue regidor de Murcia, con participación activa en la vida concejil, fiel a Carlos I cuando tiene lugar la rebelión comunera que le supuso la expulsión de la ciudad y por ello ser uno de los firmantes en la protesta de fidelidad que los expulsados firmaron en Alcantarilla en septiembre de 1520. Casado en 1507 con una rica heredera: Catalina de Puxmarín y Soto, se enrolaría más tarde en el ejército de Carlos I participando en la campaña de Argel, valorándose sus servicios con el título honorífico de gobernador y capitán y justicia mayor de la ciudad y fortaleza de Bugía.

Retirado de la vida militar, pasó los últimos días de su vida en su señorio de La Nora, cuya extensión de regadío había aumentado al obtener autorización de Carlos I para establecer cuarenta esclavos propios más veinte que podía comprar, y para cuyo concierto de trabajo mandó sacar copia del que había firmado Alfonso Fernández de Cascales con sus vasallos mudéjares de la Puebla de Cascales. No tuvo hijos en su matrimonio, pero sí fuera de él, logrando que fuera legitimado y a éste Sancho González de Arróniz dejó heredero del mayorazgo en su testamento de 2 de mayo de 1557, a sus descendientes y a falta de sucesión a la Orden de San Jerónimo; pero un inmediato codicilo antepuso a dos sobrinos por delante de la Orden; uno, Diego de Almela, con obligación de cambiar su apellido por el de González de Arróniz y poner sus armas en el lado derecho del escudo y, a falta de sucesión de éste, a Juan Fajardo, hijo de su hermana Ana y de nuevo, ahora en cuarto lugar, a la Orden de San Jerónimo.

Su heredero Sancho González de Arróniz, en su segundo matrimonio con Luz Zambrana tuvo un hijo, Alonso González de Arróniz, que muere 
dos años después de su padre. Como quiera que en el intermedio habían muerto también los otros dos sobrinos llamados a la herencia, Diego de Almela de una herida en la cabeza a consecuencia de un desafio y Juan Fajardo en la guerra de Italia, quedaba la Orden como heredera de Alonso Vozmediano. Pero las peripecias no habian acabado, porque Sáncho González de Arróniz, hijo de Vozmediano, no respetó el orden sucesorio dispuesto por su padre y dejaba heredero a su hijo Alonso y a falta de éste al Hospital de Santa María de Gracia de Murcia. Lo que iba a dar lugar al consiguiente pleito, pero pronto hubo acuerdo y el Hospital entregó los bienes de Vozmediano a la Orden de San Jerónimo y ésta, en concepto de limosna, le consignaría mil ducados. Con este acuerdo en 1579 la Orden era ya legítima propietaria y el 19 de febrero fray Diego de Murcia, prior de Baza, por disposición de los generales de la orden Hernando de Toledo y Miguel de Soto, tomaba posesión de la iglesia y lugar de La Ñora. Preocupado por los inconvenientes surgidos y atendiendo a la petición de la Orden, escribía Felipe II el 18 de julio de 1579 a la ciudad de Murcia recomendando a la Orden en su propósito de construir un monasterio en la ciudad y en sus averiguaciones por saber cuánto le pertenecia, ya que era Orden «de su devocion particular», por lo que les encargaba que hicieran cuanto fuera menester en su ayuda, y que con el mismo objeto escribía al obispo, cabildo y corregidor. El 3 de agosto fray Miguel de Alahejos, de Yuste, primer prior, se instalaba en la iglesia de San Pedro de La Nora, donde estaba enterrado Vozmediano de Arróniz y se posesionaba de la contigua casa. Por último, Beatriz de Arróniz, hija de Alonso Vozmediano, casada con Alonso Abellan Soto y Torrano, habiendo sobrevivido a su hermano Sancho, donó sus bienes al monasterio de San Pedro de La Nora el 24 de julio de 1580.

\section{EL PROYECTADO MONASTERIO DE LA RAYA}

No sería mera coincidencia el que en fecha muy cercana, por personas de la misma familia aunque distanciadas por cuestiones económicas, pero con el mismo amor a la Orden, y en lugar casi vecino, si bien al otro lado del río Segura, se pensara en la creación de un nuevo monasterio jerónimo. Cronológicamente este propósito se sitúa entre el testamento de Alonso Vozmediano (2-V-1557) y la efectividad de la toma de posesión de sus bienes por los frailes jerónimos de San Pedro de La Ñora (19-II-1579), toda vez que tiene lugar en 1566. La relación familiar 
es la de Rodrigo Puxmarín y Soto, cuñado de Vozmediano, con aportación económica y afectiva de su hermana Catalina, viuda de Vozmediano. En cuanto a la proximidad, eran escasos kilómetros los que separaban un señorío del otro, aunque el río intermedio los distanciaba. Una inundación del Segura que anegó La Puebla, Alcantarilla, La Ñora, Javalí y toda la amplia zona huertana por ambos lados del río hasta la capital, obligaría a la reconstrucción de poblados y rehacer heredades, pero también originaría nuevos lugares de asentamiento más seguros frente a las avenidas del Segura. Tras esta inundación, Rodrigo de Puxmarín, en el mismo año 1545, crearía el lugar de La Raya de Santiago entre Nonduermas y La Puebla, nombre que respondía a su condición de caballero santiaguista en cuya Orden había ingresado en 1539.

A la muerte de Vozmediano de Arróniz su viuda, Catalina de Puxmarín, hubo de mantener costoso pleito con Sancho González de Arróniz, hijo legitimado de su marido y heredero de su mayorazgo por la apropiación que su esposo había hecho de sus bienes dotales y totalidad de los gananciales, en que se incluía lo adquirido en la compra de la mitad de sus propiedades de su hermano Sancho. Recuperada su dote de trescientos cincuenta mil maravedís, más los treinta mil en que se valoraban en ropas, Catalina cedió sus propiedades a su hermano, que había abonado los gastos del pleito.

Rodrigo incrementado su mayorazgo con aportaciones de su hermana y de su hija, dispuso el 18 de abril de 1566 su testamento, estableciendo un orden sucesorio, que iría variando más tarde por la muerte de algunos de ellos. En primer lugar su hija Francisca, que fallecería antes que él; en segundo sus nietas: Catalina, esposa de Enrique Rocafull, más adelante señora de La Raya y La Ñora, y su nieta Francisca Puxmarín y Guzmán casada con Alonso de Cascales Soto; en tercer lugar era su hermana Catalina; en cuarto un hijo natural y en quinto la Orden de San Jerónimo. Poco después, el 26 de julio del mismo año, revocaba su anterior testamento y apartaba a su hijo ilegítimo de la posibilidad de herencia por no considerarlo digno de su sucesión.

La fundación del lugar de La Raya, para la que obtuvo autorización de Carlos I de poblarla con cuarenta esclavos moriscos granadinos y veinte suyos, hasta un total de sesenta, quedaría fuera de su mayorazgo, y en este pequeño señorío, anejo al mayorazgo, dispuso que se destinara superficie suficiente junto a donde ya estaba levantada la iglesia de Nuestra Señora de la Encarnación, para la creación de un monasterio jerónimo, con capacidad para doce monjes y sus servidores, conside- 
rando que las rentas que para ello destinaba no daban para más, que eran las que restaban del mayorazgo y que debía conservar igual advocación de Nuestra Señora de la Encarnación. La continuidad sucesoria dejaría sin efecto este proyecto de los hermanos Rodrigo y Catalina Puxmarín y Soto.

Cabe dejar constancia aquí de la fundación jerónima en Caravaca el año 1581, merced a la donación del presbítero Pedro de Alviar, siendo fray Cristóbal de Ortega, prior de Baza, quien se posesionó de dicha heredad, si bien, pronto, en 1638, se trasladaron al llamado "Camino del Humilladero de la Santa Vera Cruz", en donde permanecieron hasta su expulsión y expropiación en 1836. 


\section{APÉNDICE DOCUMENTAL}

\section{DOCUMENTO I}

1445-V-13, Murcia. Cláusula testamentaria del deán Fernando Alfonso de Oña, vicario de la diócesis de Cartagena.

(C. Murcia, Libro 260, fol, 13. Se sacó la primera copia en 1479).

Yten, conosco que por servicçio de Dios e de Sant Geronimo, yo ove liçençia e facultad de mi señor el obispo de Cartajena de fazer monesterio de la dicha horden de Sant Jeronimo en la mi torre e alqueria que es en Benynabia açerca de la Puebla de Santaren, la qual alqueria yo tengo el derecho enphiteotico e señorio por manda e legado que me fue fecha por Sancha Gonçalez de Aguilar, que Dios aya. En la qual alqueria fize la torre e palomares e otros hedifiçios e huerto çercado con arboles e plante vn majuelo. E yo consyderando en que mi vida seria mas prolongada e que avia facultad e bienes que pudiese fazer el dicho monesterio, me trabaje de obrar en el ende lo que pude, e conpre e ove de los moros que tenian los çensales de las dichas tierras todas las heredades de la dicha alqueria, asy las de arriba como las de la Algualeja, salvando ende doze tahullas que tiene Mosquito, moro, e otrosy, çinco o seys tahullas que tiene su yerno Pardal; los quales moros no me las quisyeron vender, e por estas tierras que estos tienen fazen de çenso tres cafiçes de trigo e medio de çebada poco mas, e mas treynta maravedis. Todas 
las otras tierras de la dicha alqueria estan agora por mias en mi poder, e fazen de çenso nueve cafiçes e quatro celemys de trigo e dos cafizes e medio de cçebada, el qual tributo e rentas es de los señores dean e cabildo de Cartajena por las misas rezadas que les dijo la dicha Sancha Gonçalez que dijesen por su anyma e de su padre e de Ferrand Yañez, su sobrino.

Asy que los señores han el dicho çenso e los otros çensos de los dichos moros Mosquito e Pardal, empero el señorio directo emphiteotico de loysmo e fadiga de las dichas heredades pertenesçen a mi con todos sus sotos e arboles que son en toda la dicha alqueria. $E$ pues a Dios plaçe que por la brevedad de mi vida el dicho monesterio no se pueda fazer ni yo tengo tantos bienes que yo pudiese dejar para lo hedificar e resdituar, e considerando que yo esto cargado de debdas e cargos de diversas personas segund paresçe por mi testamento e codiçilos, a Dios plega de me reçibir la voluntad que tenia por fecha de clemençia e pues me redimio me quiera perdonar mis faltas, menguas e pecados. Por ende mando que sy de los otros bienes que yo tengo non bastaren a pagar mis debdas e mandas, que puedan vender mis exsecutores la dicha torre e palomar e soto e tierras e hedificios e el señorio del derecho enphiteotico que yo tengo de las dichas tierras e alqueria, guardando la utilidad de los çensales del pan e dineros de los dichos doze cafizes e quatro celemis de trigo de la medida menor, e los tres cafizes de çebada e los ochenta e nueve maravedis de dineros para los dichos dean e cabildo; e la torre e palomar e huerta e hedificios que yo fize, en esto ellos non tienen derecho alguno ni entrada ni sallida, salvo que yo fago de çenso por dos tahullas e medya poco mas de la dicha huerta que fueron çengal de Maestrico del Añora, de su padre, veynte maravedis de tres blancas, las quales yo conpre e incorpore con la dicha mi huerta; el qual çensal, en cabo de la dicha huerta faza levante a donde esta fecha la casa que dizen del ortolono, ca todo lo otro es torre e palomares e fecho çimiento e establos e pajares e forno, todo es franco syn tributo alguno como la dicha señora lo tenia para sy, e asy me lo dexo.

Asy que los dichos señores han de aver de la dicha alqueria de renta çienso doze cafizes e quatro çelemis de trigo e tres cafizes de çebada de la medida pequeña e colmo e mas ochenta e nueve maravedis de tres blancas, en los quales entran los veynte maravedis que yo fago por la parte que fue de Maestrico, moro; e sacada esta renta para los dichos señores, todo lo otro pertenesçe a mi e bien creo que si aquellas heredades que yo poseo e ove de los moros se tornasen a çensar a moros del Alcantarilla o de Santaren o de la Puebla, que se avra alguna renta 
mas de lo que solie por el reparo e acçequias e arboles que yo he plantado, e lo demas si se oviere sacando lo que han de aver los dichos señores como dicho es, mando que sea vendido con la dicha torre e palomares e huerta para conplir mis debdas e mandas, e si caso fuere que se ayan de vender e el dean mi subçesor o qualquier otro persona de las personas de la Iglesia lo quisieren conprar, que les sea fecha graçia de quinientos maravedis de los que otro lego conprador quisiese dar o diese, porque sera esperança que la dicha heredad seria del cabildo. E sy los otros bienes que yo tengo abastaren o abastasen para cunplir mis debdas e mandas, mando que la dicha torre, palomares e hedifiçios e huerta e derecho emphiteotico e señorio, que sean e finquen al dean e cabildo de la Iglesia de Cartajena, e que por ellos me sean tenidos de dezir cada un año doze misas rezadas segund la costunbre e çeremonias de la Iglesia, en cada mes una misa absolviendo sobre si fuesa, sobre lo qual encargo a la conçiençia del dicho dean e cabildo e a los dichos mis exsecutores que lo fagan asi conplir, e en alguna parte de aquellos hedifiçios ruegoles que por serviçio de Dios fizieren una iglesia para los christianos que viven en aquella parte del Alcantarilla e Sangonera donde pudiesen orar e oyr misa e los sacrificios de la misa, lo qual seria cosa piadosa en favor de la fe catolica, en donde los curas de Santa Maria pudiesen yr a dezir sus misas e administrar los sacramentos a los tales christianos que por mengua de iglesia carecen dellas e andan los rectores diziendo las misas por las torres e por los lugares que no son tan honestos. 
DOCUMENTO ॥

1566-IV-18. Disposiciones de Rodrigo Puxmarin y Soto para la fundación de un monasterio jerónimo en su lugar de La Raya

(Ms. Fundación de La Raya, propiedad de D. ${ }^{a}$ María de la Concepción Sánchez Meseguer.

Lo primero, que a costa de los frutos y rentas de los dichos bienes restantes del dicho mayorazgo y anexo a el, en el lugar de la Raya de Santiago, que es anexo al dicho mayorazgo, en sitio que al presente esta edificada la iglesia de Nuestra Señora de la Encarnación, se tome en el dicho lugar todo el suelo y sitio que fuere menester y en el se haga y se edifique una casa y monasterio de la orden del señor San Geronimo, en el qual y perpetuamente para siempre jamas abiten y puedan abitar hasta doze religiosos o profesos de la dicha Orden y no mas, porque con las rentas de los dichos bienes restantes del dicho mayorazgo e de los a el anexos, los dichos religiosos y sus servidores puedan buenamente sustentarse. El qual dicho monesterio y convento y religiosos de la dicha casa que lo ayan y lleven por si, para su gasto e sustento y de la dicha iglesia y menesteres y ornamentos della, todos los frutos y rentas, derechos y pertenencias de todos los bienes restantes del dicho mayorazgo $y$ de los a el anexos. 
DOCUMENTO III

1579-VII-18, Madrid.-Felipe II al concejo de Murcia. Pidiendo que ayudaran a la Orden de $S$. Jerónimo en sus propósitos de edificar un monasterio y en averiguar la hacienda que les pertenecía, por los beneficios espirituales que proporcionarian a la ciudad.

El rey. Conçejo, justiçia, regidores, caualleros, escuderos, officiales y hombres buenos de la muy noble y muy leal ciudad de Murcia. Por parte de la orden de Sani Hieronimo se me a hecho relacion que tratan de hazer y hedifficar vn monesterio della en essa ciudad, y lo que assi para esto como para la aueriguacion de la hazienda y lo demas que conuenga les importa vuestra ayuda y medio, y por la deuocion particular que tengo a esta orden y a las cosas della y ser su intento tan bueno y esperar en nuestro Señor que ha de ser para mucho seruicio suyo y benefficio espiritual dessa ciudad, he querido encargaros tengays por muy encomendada esta fundacion, para ayudarla y hazer a la orden en todo lo que para la execución y cumplimiento dello fuere menester la buena obra y comodidad que huuiere lugar, como de vosotros confio, que demas de ser tan justo me terne en ello por seruido y en que me auiseys de lo que se hiziere; que lo mismo he escrito al obispo, cabildo y corregidor dessa ciudad para que en lo que les tocare asistan y ayuden en ello como es razon. De Madrid a XVIII de julio de MDLXXIX. Yo el rey. Por mandado de su magestad, Martin de Gaztelu. 
